state of efficiency is a problem that must be solved if we wish to guard any predisposed patient against the awful calamity of idiopathic detachment. With regard to the curative treatment I do not think any rational method has yet been suggested, and we still await the solution of how to restore and keep in proper position a retina which has become detached as a result of secondary changes in the vitreous body.

\title{
REFERENCES
}

1. Gonin, J.- "Pathogénie et anatomie pathologique des décollements rétiniens." Soc. française d'Ophtal., 1820.

2. Mortimer, J. A.-." Some observations on the prophylaxis of myopia." North of England Ophthal. Soc., 1920.

3. Trans. of the Ophthal. Soc., 1915-16.

4. Wallace, W.-."Concussion fundus changes due to gunshot wound." North of England Ophthal. Soc., 1920.

\section{EYE DISEASE RESULTING FROM MALNUTRITION}

BY

CAPTAin W. J. RUtherfurd, M.C., M.D.Glasg.,

LATE R.A.M.C.

After the Armistice I was stationed on the Franco-Belgian frontier, in a district where the civilians had endured continuous hardships and misery under the German régime since the commencement of the war in 1914.

During the final German retreat, they had been forcibly evacuated from their homes by the enemy, being sent off long distances by road or by canal into Belgium and Holland. The winter was coming on, the nights were freezing, the civilians were insufficiently clad and insufficiently nourished, and many of them were debilitated in consequence of the epidemic influenza with which they had been affected. When driven off by the Germans no arrangement seems to have been made to provide the refugees with any food.

After the Armistice they came straggling back to their old homes, returning to a district denuded of food, with the railways destroyed and the canals broken down, and with craters blown in the crossroads. The feeding of this civilian population was undertaken temporarily by the Army authorities until the French could organize their own ravitaillement; and in the First Army area even transport animals were killed, cut up, and distributed as food. In the more rural districts there was a small quantity of root crops and green vegetables remaining, and the people consumed what seed potatoes hey had been able to conceal, for the 1918 harvest and potato crop 
had been carried away by the Germans, who had also removed all the live stock.

Naturally, the health of the people suffered as the result of the miseries they endured, and in some of the districts the medical attendance was either inadequate for the time being, or else the supplies of drugs and so on were non-existent, having been removed or destroyed as the Germans withdrew. In consequence it fell to the Army medical officers to do what they could for the sick civilians in addition to carrying out their ordinary duties. This enabled us to see from within, in a way we could never have otherwise done, the sufferings the people had endured; and many an instance of high-hearted courage under tribulation, of devoted patriotism and faith, and of parental self-sacrifice presented itself to my notice while going about among the wonderful French peasantry.

During this time I attended a very large number of civilian cases varying in nature from acute appendicitis to dental extractions, and from multiple shell wounds to uterine displacement. Amongst all these cases requiring attention, there were numbers that could be definitely classified as resulting from the various sufferings and hardships undergone during the war, misery diseases due in the main to malnutrition.

A striking example of this was seen in the case of diseases of the eye. Phlyctenular conjunctivitis, ulceration, and dry conjunctivitis (xerosis) were not merely met with, but were common. Patients came with blepharitis, with hordeola, and with ordinary conjunctivitis, while measles and whooping cough were accompanied by conjunctivitis, ear discharges, and vulvo-vaginal catarrh; and I met with one case each of ruptured dacryocystitis after measles, congenital cystic swelling of the lacrymal sac, and multiple cysts of the tarsal margins; but when these rarities are eliminated, 14 cases were met with in which the eye condition may be said to have depended upon factors such as have just been described. Altogether 1,238 civilian cases of all sorts passed through my hands between the time of the Armistice and the date when I was demobilised, and of these 1.13 per cent. were of this nature, a proportion enormously greater than could ever be met with in a mixed civilian practice under normal conditions.

Treatment of these cases was sometimes difficult. They ought to have had extra nourishment, and especially required extra fat, either as cod-liver oil or in other ways, but this was impossible to procure. The 7th South Staffords, which was for some time in the same district as I was, established a soup kitchen, boiling all the spare bones that could be obtained, and distributing between 30 and 40 gallons of soup every night until the strength of the unit became greatly reduced by demobilisation and the brigade finally moved out of the area; but this could at best make little impression 
on a large population. Extra nourishment could be purchased-at a price-across the frontier in Belgium; but in a district where the people were in poverty and all work was at a standstill, it was no easy matter to expend fr. 1.25 for a single egg, or to buy butter at fr.25 the kilo. I procured from a private source a large supply of "Oxo cubes" and distributed them to the eye cases and to other special cases in which impaired nutrition was a factor of importance.

Tonics were administered to all the eye cases under treatment, either in the form of 2-grain quinine pellets, or as the compound tonic pellet containing iron, arsenic, quinine, and strychnine, that could be procured through the Army; but I could never get enough of these, my indents for supplies either being cut down before they were passed on, or not being fully met at the Field Ambulances from which I drew my supplies. Personal interviews with the Commanding Officer of the nearest Field Ambulance, and communications to the D.D.M.S. of the Corps did not result in the supply of anything like the amount of material that could have been made use of, and I carried on from hand to mouth, constantly running out of supplies, but at times succeeding in begging a little from other units, some of which were a considerable distance away. Atropin was used as a local application in all cases of eye ulcers, some of the worst of which were cauterized with liquefied carbolic acid applied either with or without preliminary anaesthesia with cocain. When the atropin ran out and could not be renewed, a small supply of homatropin was made use of. Some cases that seemed to require a nerve sedative were given bromide of potash, and this was thought to be useful. Lotions were made up to bathe the eye at home, either boric, zinc sulphate, permanganate of potash, or a mixed lotion consisting of the permanganate and zinc sulphate together; the water with which the lotion was made being always the chlorinated water taken from the water cart of the unit. It was not advisable to give the patients the solid drugs and allow them to make up their own eye lotions at home, as the local water supplies that I had had tested bacteriologically were found to be grossly polluted, and to contain both free and combined ammonia. But wherever possible the eye cases were personally treated, and I had them coming daily, over a very long period, to the room I used as an Aid Post, the ultimate results in the main being very satisfactory.

The following is a brief résumé of the cases referred to :

1. Clementine R., æt. 17 years. 6 December, 1913.. Phlyctenular ulcer on left lower sclero-corneal margin. Is convalescent from epidemic influenza, or, as she calls it, "maladie des Boches," and is very debilitated. Suffers from chlorosis and dysmenorrhoea, and has occasional syncopal attacks. 7 December. Phlyctens have developed on sclerotic of right eye as well 
10 December. Phlyctens have cleared up entirely from right eye, and left eye is nearly well too. She had several subsequent relapses, however, and was a long time under treatment.

2. Mlle de M., aet. 22 years. 11 December, 1918. Phlyctenular ulcer on outer quadrant of right sclero-corneal junction. Is chlorotic. Was a long time under treatment.

3. Léon R., aet. 8 years. 14 December, 1918. Ulcer on right cornea. Has nebula on left cornea also. Was nearly three months under treatment before he could be said to be cured.

4. Lucienne B., aet. 16 years. 18 December, 1918. Sclerotitis of right eye for past fortnight. 22 December. Has developed several small phlyctens on sclero-corneal margin. Suffers from chlorosis. This case was under treatment for about two months.

5. Justine C., aet. 8 years. 19 December, 1918. Keratitis of right eye for a year, with some slight ulceration, and scleral injection. 21 December. Small phlycten on inner sclero-corneal margin.

6. Mme. M., aet. 41 years. 23 December, 1918. Corneal ulcer on left eye, with pannus of upper corneal segment.

7. Gaston R., aet. 13 years. 7 January, 1919. Bronchitis with dry croupy cough for past four days. T. $102^{\circ} \mathrm{F}$. Zone of hyperaemia on inner quadrant of bulbar conjunctiva of right eye, suggestive of an incipient phlyctenular conjunctivitis.

8. Mme. Octave C., aet. 76 years. 21 January, 1919. Keratitis of left eye for past week, with pannus and multiple corneal ulcers.

9. Zélie P., aet. 31 years. 17 February, 1919. Ulcer on upper part of left cornea at sclero-corneal margin, probably originating in a breaking-down phlycten. Condition has been present for a month.

10. Theodule Jules F., aet. $18 \frac{1}{2}$ years. 25 February, 1919. Disorganization of left eye by a perforating corneal ulcer (keratomalacia) which ruptured three weeks ago. Dribbles at the mouth and seems semi-imbecile; has a spinal myelitis with thick speech and ataxic gait. This patient was sent to me by a returned civilian doctor with a note requesting me to get him taken into a hospital. The doctor, who knew the family, asserted that patient had a myelite specifique, but I was too pressed with work to make any attempt to verify this. Transport was procured and he was taken into a British military hospital a considerable distance away, with a view to having the disorganized eye removed.

The following are four cases of dry conjunctivitis :

1. Fernand G., aet. 34 yearś, 27 January, 1919. Xerosis, occurring as a dry conjunctivitis aftecting the outer quadrant of the bulbar conjunctiva of left eye.

2. Julienne C., aet. 22 years. 28 January, 1919. Dry conjunctivitis of left eye, with commencing pannus over lower part of cornea. 
3. Mme. Sidonie G.-A. 31 January, 1919. Dry conjunctivitis of left eye. Says that she was similarly affected seven years ago.

4. Mme. E.-P., aet. 72 years. 25 February, 1919. Mild chronic conjunctivitis, probably of the xerosis type.

It will be seen that these eye conditions were far from rare among the French civilians who had been subject to the miseries of the German domination for so long; and it is evident that prolonged malnutrition was of great importance as a causative factor, even in cases where the condition was nothing worse than an infection by the Bacillus xerosis.

E. C. Bulley has published a "Note on Xerophthalmia in Rats" as the result of certain observations on the consequence of defective diet (Biochem. Journ., Vol. XIII, No. 2, July, 1919), and in an editorial in the British Medical Journal for August 23, 1919 (p. 240) the following, with regard to such feeding experiments, occurs and is worthy of note: "In some experiments by Hopkins, the eye condition, which developed within a fortnight after the animals had been put on a diet deficient in the fat soluble factor, was conjunctivitis with ulceration of the cornea, which might go on to rupture of the cornea and dissolution of the globe." Mouquet (Rev. Méd. Vétérinaire, Nov., 1919) has recorded the occurrence of nutritional keratitis in five pet dogs whose owners had kept them on a dietary of boiled rice, proved by the event to have been insufficient for their needs. In the profound nutritional disturbances that follow upon systemic poisonings, corneal ulceration may sometimes occur : I have seen it develop in a child who died in secondary coma and acetonaemia fifty-two hours after having swallowed some laudanum that had been left out where he got access to it, and I have also seen a punched out corneal ulcer in a dog dying of a gross overdose of extract of male fern that had been administered by a veterinary surgeon.

\section{$\overline{=}$ \\ HEREDITARY CATARACT \\ BY \\ John Rowan AND James Alexander Wilson GLASGOW. GLASGOW ROYAL INFIRMARY.}

SURGEON, OPHTHALMIC INSTITUTION.

SOMEWHAT accidentally we discovered that we had each operated for cataract on different members of the same family, and our mutual investigations have enabled us to construct the following genealogical tree. It is only right to state that we have not seen all these individuals. Mrs. F. has supplied us with most of the information about her relations. All these people, except her 